Natural Hazards and Earth System Sciences (2001) 1: 3-7

(C) European Geophysical Society 2001

Natural Hazards and Earth System Sciences

\title{
Geophysical Observatory in Kamchatka region for monitoring of phenomena connected with seismic activity
}

\author{
S. Uyeda ${ }^{1}$, T. Nagao ${ }^{1}$, K. Hattori ${ }^{1}$, M. Hayakawa ${ }^{2}$, K. Miyaki $^{2}$, O. Molchanov ${ }^{3}$, V. Gladychev ${ }^{4}$, L. Baransky ${ }^{4}$, \\ A. Chtchekotov ${ }^{4}$, E. Fedorov ${ }^{4}$, O. Pokhotelov ${ }^{4}$, S. Andreevsky ${ }^{4}$, A. Rozhnoi ${ }^{4}$, Y. Khabazin ${ }^{4}$, A. Gorbatikov ${ }^{4}$, \\ E. Gordeev ${ }^{5}$, V. Chebrov ${ }^{5}$, V. Sinitzin ${ }^{5}$, A. Lutikov ${ }^{6}$, S. Yunga ${ }^{6}$, G. Kosarev ${ }^{6}$, V. Surkov ${ }^{7}$, and G. Belyaev ${ }^{1}$ \\ ${ }^{1}$ Earthquake Prediction Research Center, Tokai University, Shimizu 424-8610, Japan \\ ${ }^{2}$ Dept. of Electronics Engineering, University of Electro-Communication, Chofu-shi, Tokyo 182, Japan \\ ${ }^{3}$ Earth Observation Research Center, NASDA, Minato-ku, Tokyo 106, Japan \\ ${ }^{4}$ Institute of the Physics of the Earth Russian Academy of Sciences, 123995, Moscow D-242, Russia \\ ${ }^{5}$ Institute of Geophysical Survey Russian Academy of Sciences, Far-East Branch, Kamchatka, Russia \\ ${ }^{6}$ Institute of Geophysical Survey Russian Academy of Sciences, 123995, Moscow D-242, Russia \\ ${ }^{7}$ Moscow State Engineering Physics Institute, 115409 Moscow, Russia
}

Received: 6 June 2001 - Accepted: 23 August 2001

\begin{abstract}
Regular monitoring of some geophysical parameters in association with seismicity has been carried out since last year at the Japan-Russian Complex Geophysical Observatory in the Kamchatka region. This observatory was organized in connection with the ISTC project in Russia and was motivated by the results of the FRONTIER/RIKEN and FRONTIER/NASDA research projects in Japan. The main purpose of the observations is to investigate the electromagnetic and acoustic phenomena induced by the lithosphere processes (especially by seismic activity). The seismicity of the Kamchatka area is analyzed and a description of the observatory equipment is presented. At present, the activity of the observatory includes the seismic (frequency range $\Delta \mathrm{F}=0.5-40 \mathrm{~Hz})$ and meteorological recordings, together with seismo-acoustic $(\Delta \mathrm{F}=30-1000 \mathrm{~Hz})$ and electromagnetic observations: three-component magnetic ULF variations $(\Delta \mathrm{F}=0.003-30 \mathrm{~Hz})$, three-component electric potential variations $(\Delta \mathrm{F} \leq 1.0 \mathrm{~Hz})$, and VLF transmitter's signal perturbations $(\Delta \mathrm{F} \sim 10-40 \mathrm{kHz})$.
\end{abstract}

\section{Introduction}

Recently, the interest to investigation of the electromagnetic and acoustic phenomena connected with lithosphere processes is increasing considerably. Some experimental results,

Correspondence to: V. Gladychev (glad@uipe-ras.scgis.ru) which illustrate the connection between anomalous electromagnetic phenomena and acoustic phenomena with earthquake preparation, were presented in a rather comprehensive collection of papers edited by Hayakawa $(1994,1999)$. It is evident that further investigation of these connections as well as the simultaneous observations of a wide complex of different geophysical fields is necessary. For this purpose the Complex Geophysical Observatory (hereafter CGO) was established in the Kamchatka peninsula seismic active region by Russian and Japanese scientists during 1999. It is located in Karimshino, $\left(52.94^{\circ} \mathrm{N}, 158.25^{\circ} \mathrm{E}, \mathrm{L}=2.1\right)$ at a distance of about $50 \mathrm{~km}$ from Petropavlovsk-Kamchatskiy and none of the sources of industrial noise are observed close to this particular area. The following phenomena are observed by CGO: variations in the ULF/ELF magnetic field, geoelectric fields (telluric currents), VLF signals from navigation radio stations and acoustic emission. Some meteorological parameters (atmospheric wind velocity, humidity, air temperature, air pressure) are also recorded.

\section{Seismicity of Kamchatka region}

The region of Kamchatka, together with the Kurile and the Japanese Islands forms the tectonically active northwest margin of the Pacific Ocean. That represents a zone of the Pacific plate subduction beneath the Eurasian continent. Thus, the seismotectonic processes all over this zone are similar and interconnected (Fig. 1). 


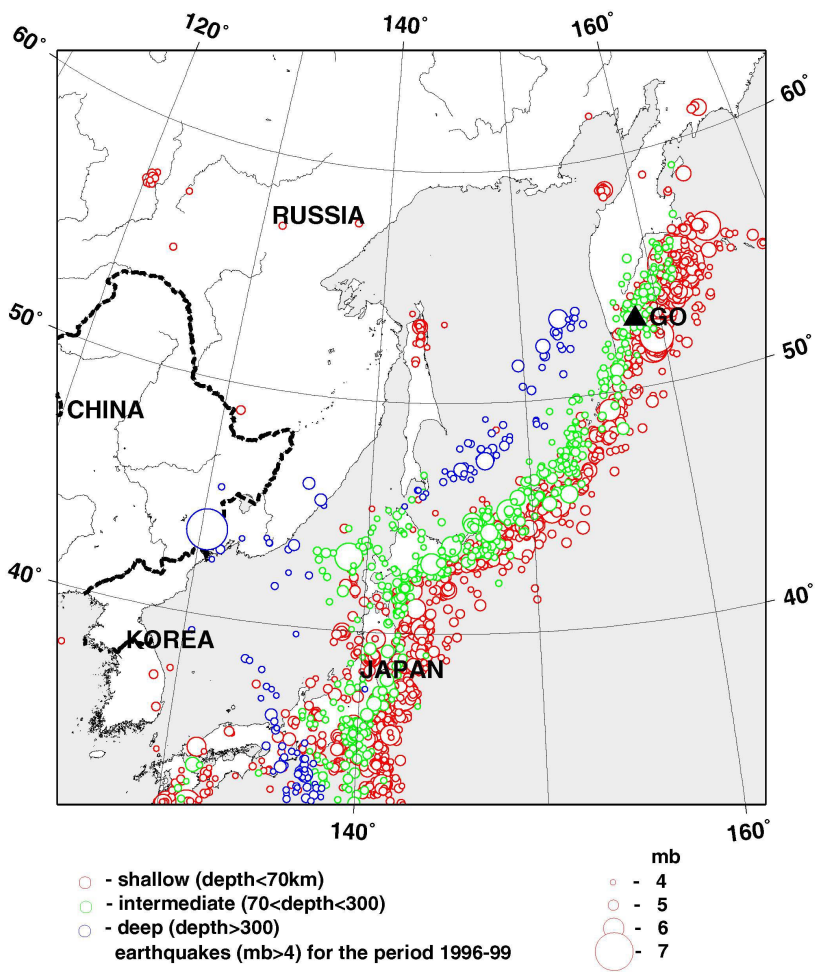

Fig. 1. The overview map of the northwest margin of the Pacific Ocean with its seismicity; the triangle shows the location of the CGO Karimshino.

The Kamchatka region itself is characterized by extremely strong seismicity: during the last 30 years, more than 30 large earthquakes with magnitudes of $\mathrm{Ms} \geq 6.5$ (Fig. 2) and about 280 events with $\mathrm{Ms} \geq 5$ have occurred. More than 700 earthquakes with $\mathrm{Ms} \geq 2.5$ occur here every year. The earthquake number distribution versus the distance from the observatory show a noticeable domestic weak seismicity: no EQ with $\mathrm{M} \geq 3.5$ has been observed during at least 40 years at a distance of less than $50 \mathrm{~km}$ from the observatory.

The seismicity of the Kamchatka is described in detail in many recent works. New features are revealed including the double-planed spatial distribution of earthquake hypocenters (Fig. 3), signs of self-similarity in statistics of focal mechanisms, characteristics of seismic regime and its variations before and after strong earthquakes, etc. (Lutikov and Kuchai, 1998; Lutikov, 2000; Yunga and Rogozin, 2000).

Seismic monitoring in Karimshino includes the weak earthquakes representative registration. The earthquakes with magnitudes of Ms $>0.5-1.0$ within the radius of 50$70 \mathrm{~km}$ from the observatory were registered. Observation of seismic wave forms at the observatory is necessary for the estimation of natural and industrial local seismic noise and the measuring of earthquake waveform parameters (including time, amplitude, sign and particle motion of the main seismic phase, S-wave splitting, coda, etc.). An example of earthquake waveforms recorded at Karimshino during four days in June 2000 is displayed in Fig. 4. The above men-

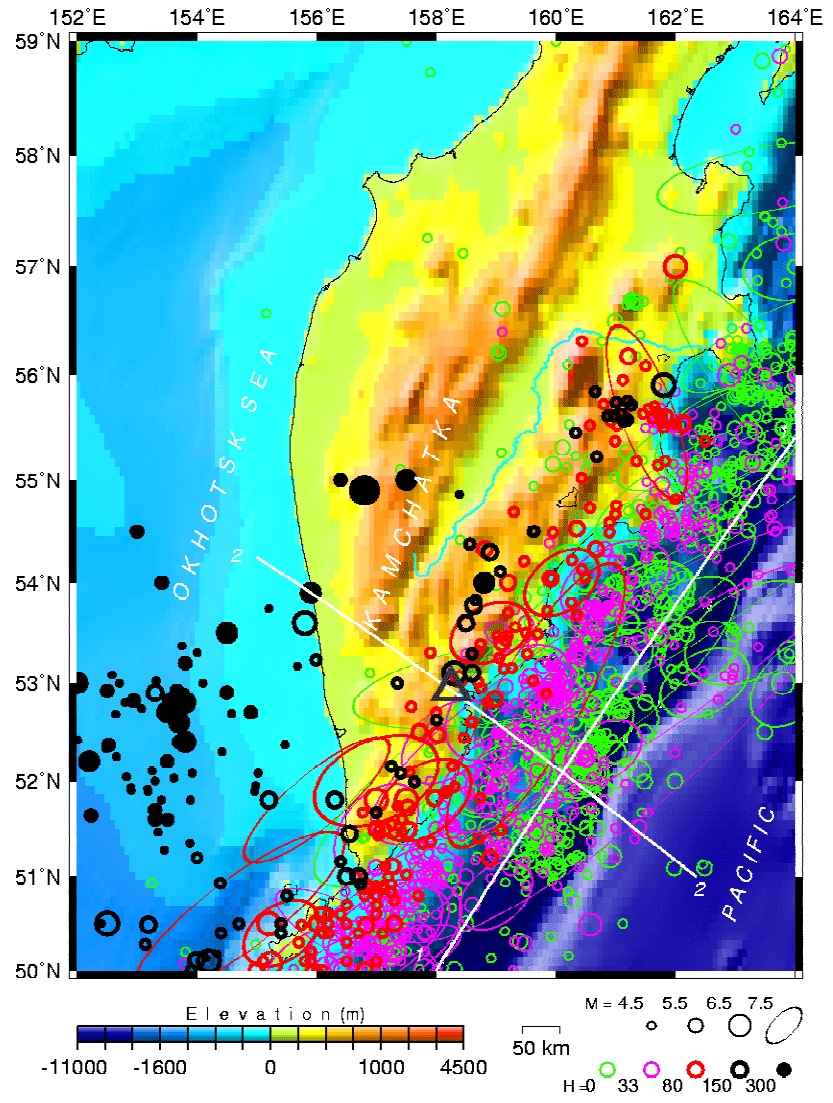

Fig. 2. The seismicity of Kamchatka peninsula. Strong earthquakes $(\mathrm{Ms} \geq 4.5)$ are shown as ellipses, with a large axis oriented as the earthquake origins appear; the triangle shows the location of the CGO Karimshino.

tioned parameters are chosen as the most appropriate ones which may correlate with variations in the electric and magnetic fields. After observation of seismic wave fields over several months, it is possible to estimate the average level of seismic noise and the typical earthquake waveforms.

\section{Complex Geophysical Observatory}

CGO consists of three separate measuring systems for observations of:

1. Seismic waves, ULF/ELF magnetic field and acoustic emissions,

2. Telluric currents,

3. VLF signals from navigation radio stations.

The First System of CGO includes the Distant Measuring System and Data Acquisition Base, which is placed $500 \mathrm{~m}$ apart from one another in order to minimize the noise level. Signal data and power supply cables connect both parts. The Distant Measuring System includes:

1. Geophysical measuring devices; Seismometer, Magnetometer, Acoustic seismometer, 


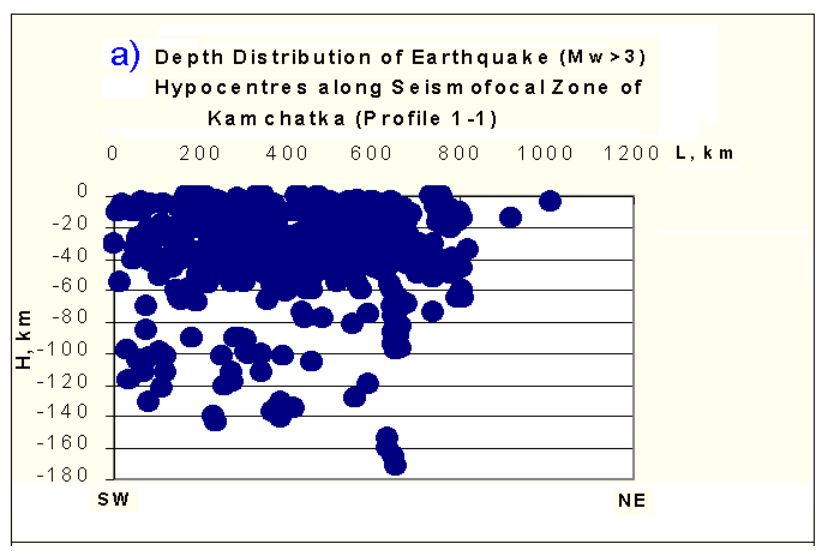

Fig. 3a. The depth distribution of the earthquake hypocenters along the seismofocal zone of Kamchatka. (profile 1-1 in Fig. 2).

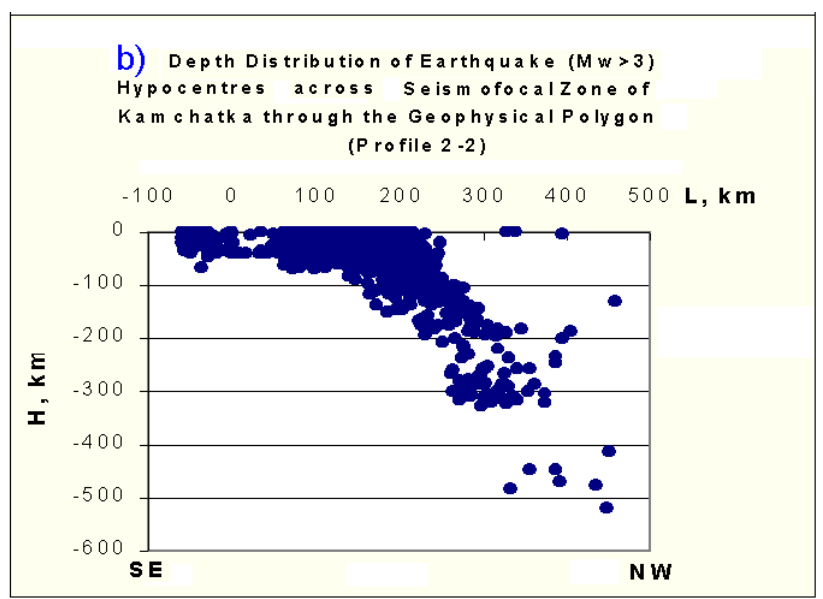

Fig. 3b. The depth distribution of the earthquake across the seismofocal zone through the region of the CGO (profile 2-2 in Fig. 2). One can see such a feature as a double-planed spatial distribution of the earthquake hypocenters at the depth range of $200-300 \mathrm{~km}$.

2. Data converter complex, which consists of

(a) Analog-digital converters (ADC); its inputs are connected to the outputs of the geophysical measuring devices;

(b) Control and data buffer module, which collects digital information from ADC, provides raw processing and buffer storage, records time marks and transmits information into the Data Acquisition Base in an automatic regime;

\section{Distant power supply (batteries).}

The computer system of the Data Acquisition Base creates the archive and records it in the Magneto-Optical drive. A GPS receiver provides precise time signals, which enter the Computer and Distant Measuring System.

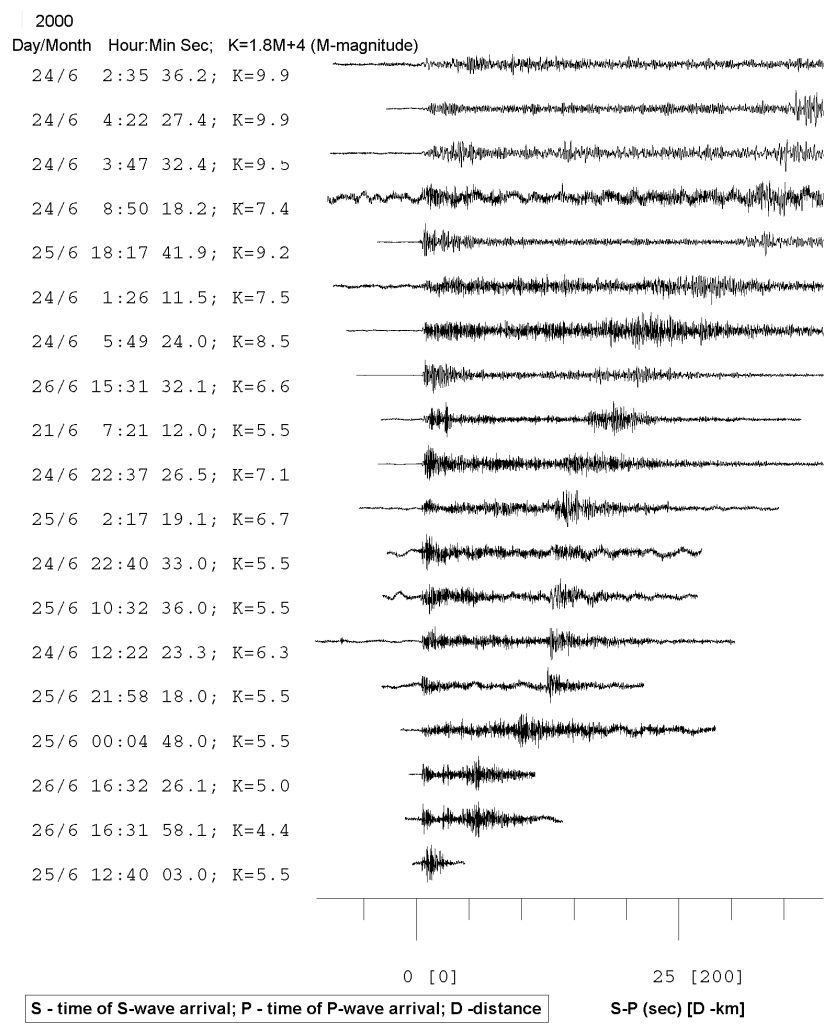

Fig. 4. The earthquake waveforms recorded at Karimshino during the following four days: 21, 24, 25, and 26 June 2000. The range of the hypocentral distances is $3-240 \mathrm{~km}$. The minimal distance of $3 \mathrm{~km}$ was observed for the event on 26 June, 12:40. The hypocentral distance for the events on 26 June, 16:31 and 26 June, 16:32 is about $30 \mathrm{~km}$. Other earthquakes with hypocentral distances of 100$240 \mathrm{~km}$ are primarily connected to the subduction Pacific plate.

3.1 The basic characteristics of geophysical measuring devices

Seismometer. The measurements of 3 components of ground displacement velocity is provided by the seismometer SM-3 in the frequency range of $0.5-40 \mathrm{~Hz}$ with a sensitivity threshold of $10-8 \mathrm{~m} / \mathrm{s}$ and a dynamic range of $90 \mathrm{Db}$.

Magnetometer. Three axial induction magnetometer measures geomagnetic field variations in the frequency range of $0.003-40 \mathrm{~Hz}$. The sensitivity threshold is better than $20 \mathrm{pT} / \mathrm{Hz}^{1 / 2}$ at a frequency of $0.01 \mathrm{~Hz}$, and it corresponds to $0.02 \mathrm{pT} / \mathrm{Hz}^{1 / 2}$ at frequencies above $10 \mathrm{~Hz}$. The low threshold of the magnetometer sensitivity and the Karimshino low level of magnetic noise at high frequencies allows one to observe up to 7 Schuman resonances (Fig.7)

Acoustic Seismometer. The acoustic emission receiver is based on a mechanical system with a ceramic transducer. The signal from the ceramic transducer increases with the frequency as $f^{2}$ and the resonant frequency of the sensor are at $1200 \mathrm{~Hz}$, so that the working range of the instrument falls in the pre-resonant range.

The instrument includes a sensor in a metal box, as well as amplifier and filter blocks (Fig. 8). The last one contains four band-pass filters with central frequencies of $30,160,500$ 

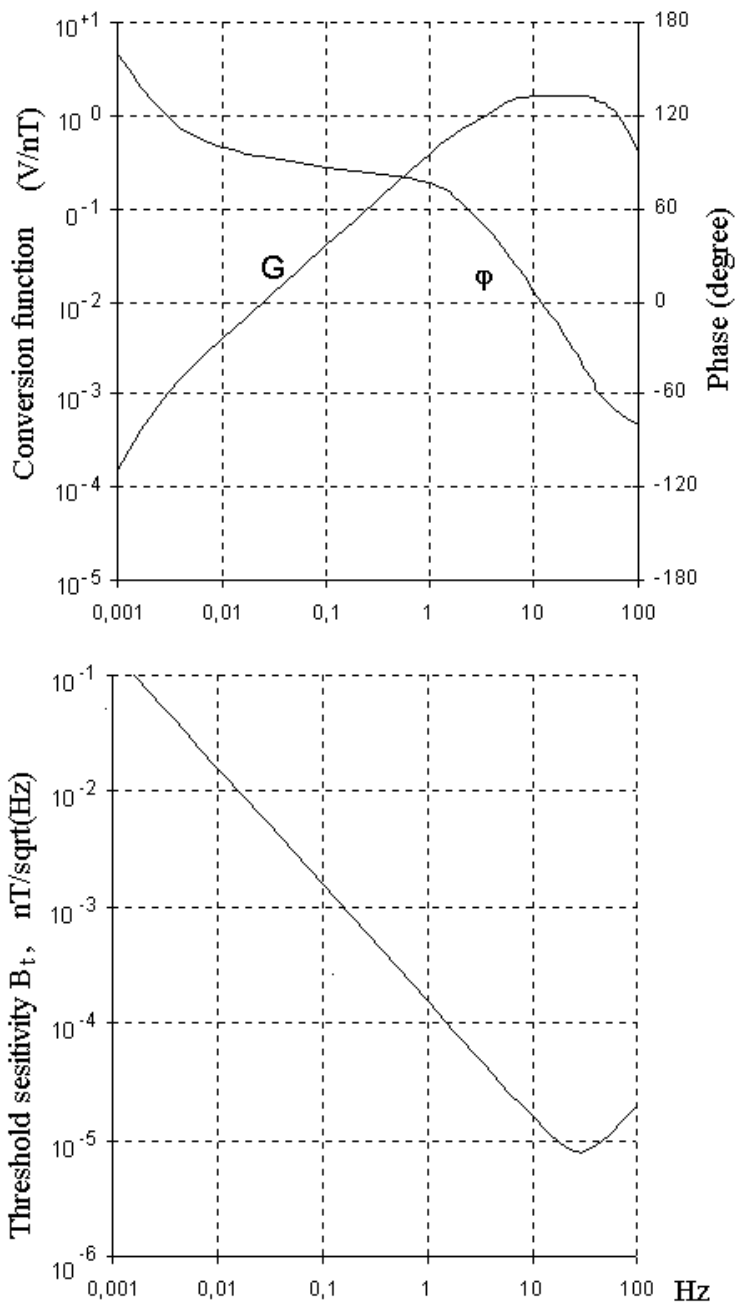

Fig. 5. The magnetometer characteristics: (a) an absolute value of gain $(G)$ and phase $(\varphi)$ of the magnetic sensor conversion function, (b) threshold sensitivity of the sensor.

and $1000 \mathrm{~Hz}$. After filtration the signals are smoothed by an integrator, and then arrive at the ADC. The sensor of the seismic acoustic emission is installed into the bore-hole (depth is about $30 \mathrm{~m}$ ) with the steel pipe.

\subsection{The Second system of CGO}

Measurements of telluric currents are carried out by nonpolarised electrodes buried in the ground (Fig. 9). Common electrode 1, together with electrodes 2, 3, 4 forms three NS dipoles of different lengths: $80 \mathrm{~m}, 230 \mathrm{~m}$ and $470 \mathrm{~m}$. The same common electrode 1 , together with electrodes $5,6,7$ forms three EW dipoles of the same length. A so-called VAN-method (Varotsos and Lazaridou, 1991) uses such a multiple-dipole measuring system in order to search for an earthquake precursor. According to the VAN-method, the telluric current signals SES (Seismic Electric Signals), which precede an earthquake, are characterised by the condition: $\Delta \mathrm{V}_{\mathrm{i}} / \mathrm{l}_{\mathrm{i}}=$ constant, where $\Delta \mathrm{V}$ indicates a change in the potential difference measured by the dipole, $l$ is the length
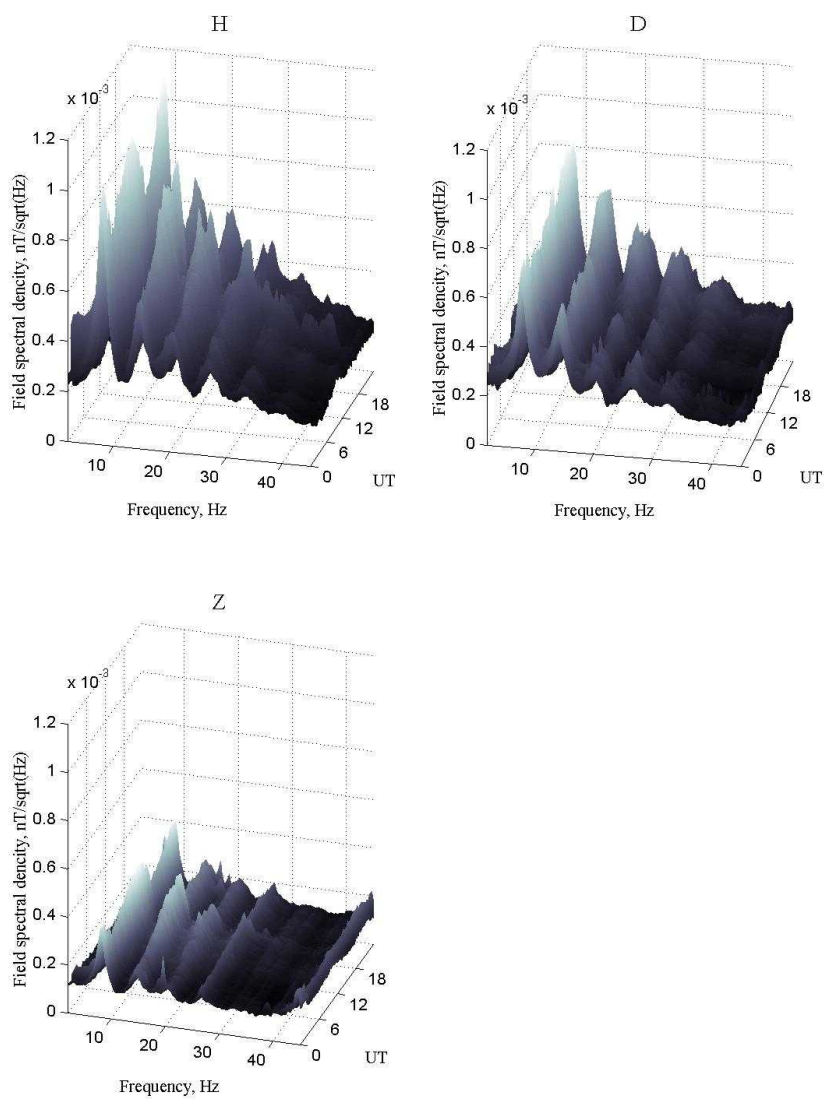

Fig. 6. An example of the daily variations in the Schuman spectra.

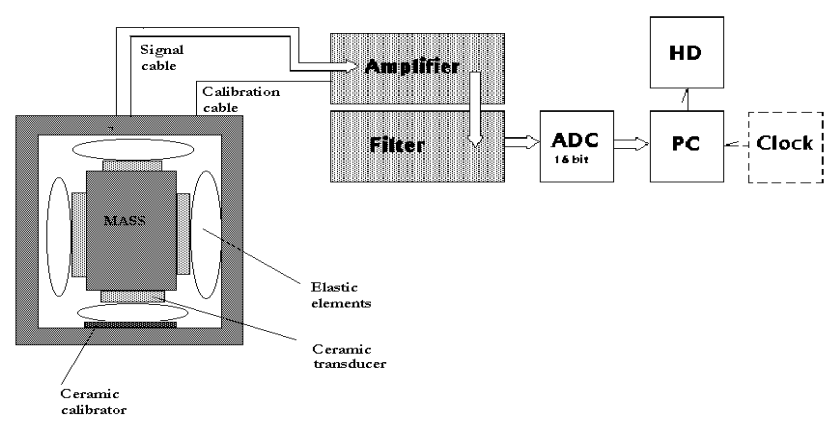

Fig. 7. The scheme of the acoustic emission receiver.

of the dipole and $i$ represents the numbers of three dipoles groups in the same direction $(i=1,2,3$ for NS and 4,5,6 for EW). The unit LS3300Ptv of the Hakusan corporation is utilized for processing the potential differences $\Delta \mathrm{V}_{i}(i=1-6)$. The Notch filters of the Logger cut out the signals with frequencies of $50 \mathrm{~Hz}, 60 \mathrm{~Hz}$ and their harmonics. The rest of the signals are digitised by A/D converters (sampling rate $6 \mathrm{sp} / \mathrm{min}$, dynamic range $2 \mathrm{~V}, 20 \mathrm{bit}$ ) and recorded by an intermediate Memory with a capacity of $1.6 \mathrm{Mb}$. The accumulated data are transmitted into a PC once every two weeks. 


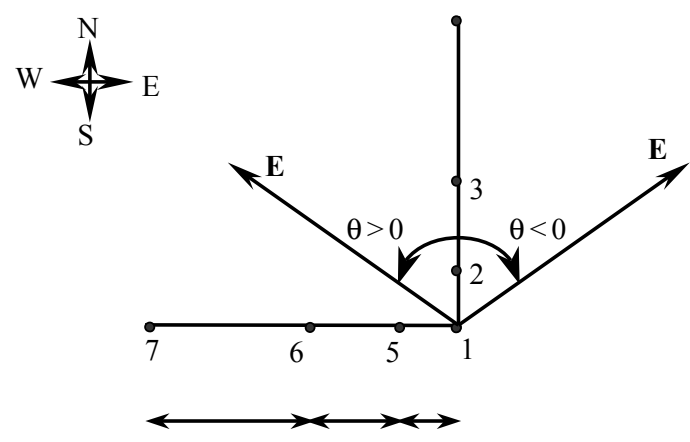

Fig. 8. The scheme of the positioning of the telluric currents measuring electrodes.

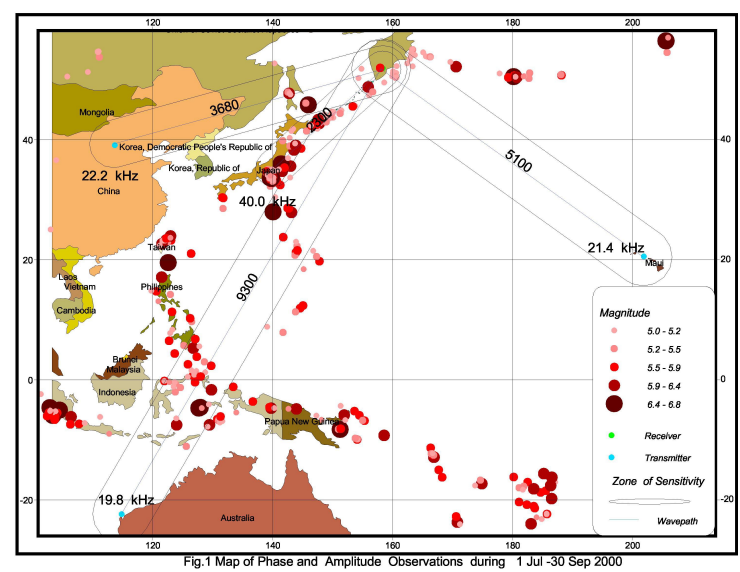

Fig. 9. The diagram of radio transmitters and receiver locations together with the distribution of EQ $(M \geq 5)$ epicenters for a time periodof 1 July 2000 - 30 September 2000 . The areas of the assumed receiver sensitivity for each wave path, which are stretched along these wave paths and have the width of two Frenels zones, are also displayed.

\subsection{The third system of CGO}

Installed at Petropavlovsk-Kamchatskiy AbsPAL (Absolute Phase \& Amplitude Logger), this system measures the phase and amplitude of the signals from navigation radio transmitters in Japan $\left(36^{\circ} 11^{\prime} \mathrm{N}, 139^{\circ} 51^{\prime} \mathrm{E}\right)$, Australia $\left(21^{\circ} 49^{\prime} 01^{\prime \prime} \mathrm{S}, 114^{\circ} 09^{\prime} 50^{\prime \prime} \mathrm{E}\right)$, China $\left(40^{\circ} 06^{\prime} \mathrm{N}, 113^{\circ} 05^{\prime} \mathrm{E}\right)$ and Hawaii $\left(21^{\circ} 25^{\prime} 30^{\prime \prime} \mathrm{N}, 158^{\circ} 09^{\prime} 20^{\prime \prime} \mathrm{W}\right)$. The diagram of the radio transmitters and the receiver location is displayed in Fig. 10. The frequencies of the transmitters are $40 \mathrm{KHz}$, $19.9 \mathrm{KHz}, 22.2 \mathrm{KHz}$ and $21.4 \mathrm{KHz}$, correspondingly. There are some evidences that anomalous variations of phase and amplitude are observed along wave paths crossing over the regions with increasing seismic activity.

\section{References}

Hayakawa, M. and Fujinawa, Y.: (Eds) in: Electromagnetic Phenomena Related to Earthquake Prediction, Terra Sci. Publ. Comp., Tokyo, p. 677, 1994.

Hayakawa, M.: (Ed) in: Atmospheric and Ionospheric Electromagnetic Phenomena Associated with Earthquakes, Terra Sci. Publ Comp., Tokyo, p. 995, 1999.

Lutikov, A. and Kuchay, M. S.: Seismicity time variation in the areas of occurense a number of strong earthquakes in the North Caucasus, Journal of earthquake prediction research, 7, 1, 76-82, 1998.

Lutikov, A. I.: Relations between energy classes and magnitude Ms of Kamchatkan earthquakes, Volc. Seis., 21, 699-703, 2000.

Varotsos, P. and Lazariou, M.: Latest aspects of earthquake prediction in Greecebased on seimic electric signals, Tectonophysics, 188, 3/4, 321-347, 1991.

Yunga, S. L. and Rogozhin, E. A.: Seismicity, focal mechanisms and seimotectonic deformation within active blocks of lithospere, in: Neotectonics, geodynamics and seismicity of Northern Eurasia, Publ. UIPE RAS., Moscow, (in Russian), 383-420, 2000. 